\title{
El Principio Kompetenz - Kompetenz del arbitra- je comercial internacional en la jurisprudencia del tribunal supremo de justicia venezolano
}

The Principle Kompetenz-Kompetenz of international commercial arbitration in the case law of the Supreme Court of Justice of Venezuela

Dra. Sorily Carolina Figuera Vargas, PhD (Autora corresponsal)

Profesora Titular PUCE (Facultad de Jurisprudencia)

Dra. Sonia Vargas Torres, Mgtr.

Abogada e Investigadora del Instituto Jurídico Bartolomé de las Casas

Juan Fernando Puertas Barahona

Investigador jurídico

Artículo Original (Científico)

RFJ, No. 4, 2018, pp. 135-157, ISSN 2588-0837

RESUMEN: desde la creación del Tribunal Supremo de Justicia venezolano (TSJ) en 1999, una serie de sentencias dictadas por la Sala Político Administrativa fijaron un antecedente contraproducente al desconocer el principio kompetenz - kompetenz propio del arbitraje comercial internacional. Así, por ejemplo, en las sentencias que se pronunciaron sobre los asuntos Hyundai de Venezuela C.A. c. Hyundai Motor Company del año 1999 y Consorcio Barr S.A c. Four Seasons Caracas C.A., ese Máximo Tribunal omitió dicho principio. A pesar de ello, luego el TSJ dio un viraje y en el asunto Astivenca Astilleros de Venezuela, C.A. c. Oceanlink Offshore III A/S del año 2010, dictó una sentencia con carácter vinculante, que constituyó un decisivo respaldo al principio kompetenz - kompetenz en el arbitraje comercial internacional. En las próximas páginas se presenta un análisis jurisprudencial, enfocado en diferentes sentencias dictadas por el TSJ, donde se estudia la evolución de la institución del arbitraje comercial internacional y el principio kompetenz - kompetenz en el sistema jurídico de ese país suramericano. Se pretende entonces, incentivar la disertación sobre este tema tan importante en la esfera del Derecho de los Negocios Internacionales 
PALABRAS CLAVE: principio kompetenz-kompetenz, arbitraje comercial internacional, claúsula compromisoria, poder judicial, Tribunal Supremo de Justicia Venezolano.

ABSTRACT: since the creation of the Venezuelan Supreme Court of Law in (SCL) 1999, a series of sentences passed by the PoliticalAdministrative Chamber set a counterproductive precedent by not recognizing the kompetenz - kompetenz principle proper of international commercial arbitration. For instance, in the sentences that were pronounced on the subjects Hyundai of Venezuela C.A. c. Hyundai Motor Company of 1999 and Consortium Barr S.A c. Four Seasons Caracas C.A., the Supreme Court omitted that principle. In spite of the sentences, then the SCL took on a new direction and in the subject Astivenca Astilleros of Venezuela, C.A. c. Oceanlink Offshore III A/S of 2010, passed a sentence of binding nature, which constituted a decisive support to the kompetenz - kompetenz principle in international commercial arbitration. In the next pages is presented a jurisprudence analysis focus on the different sentences passed by the SCL, where it is studied the evolution of institution of the international commercial arbitration and the kompetenz - kompetenz principle in the legal system of this south American country. It intends to encourage the dissertation of this important matter in the International Business Law sphere.

KEY WORDS: kompetenz-kompetenz principle, international commercial arbitration, arbitration clause, Venezuelan Supreme Court of Law.

\section{INTRODUCCIÓN}

Actualmente se puede hablar de una situación generalizada de crisis en los sistemas de administración de Justicia en los diversos países que integran la comunidad internacional. Tal realidad ha traído como consecuencia una constante búsqueda de nuevos métodos alternativos de resolución de conflictos, frente a la vía judicial tradicional. Así pues, se ha confirmado la necesidad de impulsar el arbitraje comercial como alternativa frente a los mecanismos jurisdiccionales, en la constante búsqueda de impulsar un mayor acceso a la justicia, que permita a la vez descongestionar a las instituciones encargadas de administrar justicia (Araúz Ramos, 2014). 
En los sistemas jurídicos ha surgido entonces la necesidad imperiosa que estén garantizadas las reglas que respeten, garanticen y reconozcan la autonomía que tienen las partes al celebrar un contrato, de someter las controversias que surjan del mismo, a un arbitraje comercial. Además, ese mismo sistema judicial debe ofrecer los mecanismos para avalar la ejecución del laudo arbitral nacional o internacional dentro de su territorio. La relevancia del arbitraje comercial como medio alterno de solución de conflictos ha sido corroborada a lo largo de los años por organismos internacionales, convenciones, legislaciones dentro de los órdenes jurídicos internos de diversos países.

Ahora bien, en el contexto del sistema jurídico venezolano, se puede decir que tradicionalmente ha existido cierta resistencia al arbitraje por parte de algunos de los órganos del Poder Judicial. Principalmente por estimar que los pactos arbitrales constituyen una derogatoria de la jurisdicción de los tribunales judiciales. Evidentemente, tal argumento resulta inadmisible, porque implicaría el desconocimiento de los pilares fundamentales que respaldan este mecanismo, como una institución viable y efectiva que integra el sistema de justicia de ese país (Constitución de la República Bolivariana de Venezuela, 1999, artículos 253 y 258).

En la primera década del Siglo XXI la Sala Político Administrativa del Tribunal Supremo de Justicia de la República Bolivariana de Venezuela, dictó una serie de sentencias que desconocieron el principio kompetenz - kompetenz, entendido como la facultad que tiene el tribunal arbitral internacional para decidir sobre su propia competencia; así como, sobre las objeciones relativas a la existencia o la validez de la cláusula compromisoria (Ley de Arbitraje Comercial, 1998). Esta tendencia jurisprudencial trajo como consecuencia la falta de reconocimiento de la validez del acuerdo arbitral, que, en ejercicio de autonomía de la voluntad, las partes incluían en sus contrataciones de carácter internacional.

A pesar de lo antes expuesto, a continuación, se concluirá como la perspectiva del Tribunal Supremo de Justicia venezolano cambió en relación al principio kompetenz - kompetenz. Por ejemplo, la Sala Constitucional en el caso Astivenca Astilleros de Venezuela, C.A. c. Oceanlink Offshore III A/S, en el año 2010 dictó una decisión con carácter vinculante, que constituyó un decisivo respaldo a este principio propio del arbitraje comercial internacional (Tribunal Supremo de Justicia, Sala Constitucional, 2010). 


\section{CARACTERIZACIÓN DEL ARBITRAJE COMERCIAL INTERNACIONAL DESDE LA PERSPECTIVA DEL ORDENA- MIENTO JURÍDICO VENEZOLANO}

El arbitraje es un método de resolución de disputas alternativo a la administración de justicia. Se caracteriza por ser un procedimiento privado en el que las partes, en uso de su autonomía de la voluntad, acuerdan someter determinada disputa a uno o varios árbitros a los que autorizan para resolver la controversia mediante una decisión definitiva y obligatoria para las partes. Cuando una disputa se somete a arbitraje, se excluye la posibilidad de recurrir a la administración de justicia en relación con esa misma controversia. Por eso, es imprescindible el consentimiento de ambas partes. Una vez que las partes han pactado el sometimiento a arbitraje, cada una queda vinculada por dicho compromiso (Hung Vaillant, 2001, pp. 48-49). Es de destacar que el acuerdo de arbitraje es un convenio, en la cual:

Las partes deciden someter a arbitraje todas las controversias o ciertas controversias que hayan surgido o puedan surgir entre ellas respecto de una determinada relación jurídica, contractual o no contractual. El acuerdo de arbitraje podrá acoger la forma de una cláusula compromisoria incluida en un contrato o la forma de un acuerdo independiente (Naciones Unidas, CNUDMI, 2006, Art. 7).

En virtud del acuerdo de arbitraje las partes se comprometen a someter la resolución de sus controversias a la decisión de árbitros, a la vez que, renuncian a hacer valer sus pretensiones ante los jueces. El acuerdo de arbitraje es exclusivo y excluyente de la jurisdicción ordinaria. Esto según lo prevé el artículo 7 de la Ley Modelo de la CNUDMI sobre Arbitraje Comercial Internacional de 1985, con enmienda de (2006) y el artículo 5 de la Ley de Arbitraje Comercial venezolana (1998).

El artículo 6 de la Ley de Arbitraje Comercial venezolana consagra como requisito formal del acuerdo de arbitraje, "la condición de constar por escrito en cualquier documento o conjunto de documentos que dejen constancia de la voluntad de las partes de someterse a arbitraje" (1998). Asimismo, dice la norma que "la referencia hecha en un contrato a un documento que contenga una cláusula arbitral, constituirá un acuerdo de arbitraje siempre que dicho contrato conste por escrito y la referencia implique que esa cláusula forma parte del contrato". En el caso específico de los contratos de adhesión y los contratos normalizados, exige la disposición que la manifestación de voluntad de 
someter el contrato a arbitraje deberá "hacerse en forma expresa e independiente" (1998). Ahora bien, sobre la condición comercial del arbitraje expondremos los planteamientos de la segunda nota al pie de página de la Ley Modelo de la CNUDMI sobre Arbitraje Comercial Internacional, en donde se señala que:

Debe darse una interpretación amplia a la expresión "comercial" para que abarque las cuestiones que se plantean en todas las relaciones de índole comercial, contractuales o no. Las relaciones de índole comercial comprenden las operaciones siguientes, sin limitarse a ellas: cualquier operación comercial de suministro o intercambio de bienes o servicios, acuerdo de distribución, representación o mandato comercial, transferencia de créditos para su cobro (factoring), arrendamiento de bienes de equipo con opción de compra (leasing), construcción de obras, consultoría, ingeniería, concesión de licencias, inversión, financiación, banca, seguros, acuerdo o concesión de explotación, asociaciones de empresas y otras formas de cooperación industrial o comercial, transporte de mercancías o de pasajeros por vía aérea, marítima, férrea o por carretera (2006).

Así mismo, como criterios para determinar la internacionalidad del arbitraje, se tomarán en cuenta los siguientes:

a) El domicilio, la nacionalidad, la residencia o el asiento principal de las partes;

b) El domicilio, la nacionalidad o la residencia de o los árbitros,

c) El lugar de celebración del contrato objeto de la controversia;

d) El lugar de ejecución de dicho contrato;

e) La nacionalidad o el asiento principal de la institución arbitral;

f) El lugar donde el laudo arbitral será ejecutado;

g) El lugar del arbitraje,

h) El derecho escogido por las partes para regular el acuerdo arbitral, el fondo de la controversia y/o el procedimiento arbitral (Sánquiz Palencia, 2005, pp. 23-24). 
El estudio jurisprudencial que se presentará a continuación se circunscribirá al ámbito del arbitraje comercial de carácter internacional, por ser esta la línea de investigación seguida por las autoras. Se descartaron entonces aquellas sentencias dictadas por el Tribunal Supremo de Justicia (TSJ) venezolano, que si bien se relacionaban con el arbitraje comercial y el principio kompetenz - kompetenz, su desarrollo era netamente doméstico.

En otro orden de ideas, destacaremos la existencia de dos categorías dentro del arbitraje comercial, el institucional y el independiente o ad hoc. Clasificación contenida en el artículo 2 de la Ley de Arbitraje Comercial venezolana. Al momento de incluir una cláusula de arbitraje en un contrato, las partes deben decidir si desean que dicho arbitraje sea de tipo institucional o si prefieren recurrir a un arbitraje independiente.

El arbitraje institucional, también denominado por la doctrina como arbitraje administrado, se realiza de acuerdo a los reglamentos de los Centros de Arbitraje. Las normativas de dichas instituciones deben regular todo lo concerniente a la constitución del tribunal, las notificaciones, la recusación y reemplazo de árbitros y toda la tramitación del proceso. Asimismo, deben incluir el procedimiento para la elaboración de la lista de árbitros y las tarifas de sus honorarios; así como, la de gastos administrativos del proceso (Betancourt, 2010).

En Venezuela los Centros de Arbitrajes donde se puede desarrollar esta forma de resolución de controversias en su categoría institucional, son: a) el Centro de Arbitraje de la Cámara de Comercio de Caracas; b) Centro Empresarial de Conciliación y Arbitraje (CEDCA); y el c) Centro de Arbitraje de la Cámara de Comercio de Maracaibo. En el ámbito del arbitraje comercial internacional destacan, por ejemplo, la Corte Internacional de Arbitraje de la Cámara de Comercio Internacional de París (CCI), el Centro de Arbitraje Comercial y de Mediación para las Américas (CAMCA) o el Centro de la Asociación Americana de Arbitraje (AAA).

El arbitraje independiente o ad hoc es el regulado por las partes sin intervención de los centros de arbitraje. Las partes determinan las normas de procedimiento arbitral, los efectos, el nombramiento de los árbitros y cualquier otra cuestión concerniente al arbitraje, respetando la legislación vigente sobre la materia (Araque Benzo, 2011, pp. 56-57). 
Además, cabe resaltar la figura del árbitro, quien es la persona natural elegida por las partes para sustanciar y solucionar la controversia sometida a su decisión. En pocas palabras, viene a ser el juez del proceso, cuya misión comienza con la aceptación y avocamiento al conocimiento de la causa y termina con el laudo arbitral (Valeri Albornoz, 2011, pp. 672-673).

Existen dos clases de árbitros, según lo consagra el artículo 8 de la Ley de Arbitraje Comercial venezolana, estos son los árbitros de derecho y los árbitros de equidad. "Los primeros deberán observar las disposiciones de derecho en la fundamentación de los laudos. Los segundos procederán con entera libertad, según sea más conveniente al interés de las partes, atendiendo principalmente a la equidad" (1998). De darse el caso en el que las partes no hubieren hecho mención sobre el carácter de los árbitros, entonces, se entenderá que estos actuarán como árbitros de derecho. Finalmente añade esta disposición, que "los árbitros tendrán siempre en cuenta las estipulaciones del contrato y los usos y costumbres mercantiles" (1998).

Cabe considerar igualmente, que:

Los árbitros nombrados por acuerdo de las partes no podrán ser recusados sino por causales sobrevivientes a la designación. Los nombrados por el Juez o por un tercero, serán recusables dentro de los cinco (5) días siguientes a la fecha en que se notifique la instalación del Tribunal Arbitral, de conformidad con el procedimiento señalado en la ley (Ley de Arbitraje Comercial, 1998, Art. 35).

Del artículo 35 al 40 de la Ley de Arbitraje Comercial se encuentra la regulación del procedimiento de recusación de los árbitros.

El laudo es la decisión de los árbitros, ostentando igual valor de cosa juzgada que el de una sentencia y acarreando la posibilidad de ejecución forzosa. El laudo se distingue porque no puede ser recurrido como una sentencia; es decir, no existe una segunda instancia arbitral. Cuando el laudo es dictado solo cabe interponer ante los tribunales ordinarios una demanda de anulación, que solo puede basarse en motivos formales y tasados (por ejemplo, que los árbitros hayan decidido sobre cuestiones que las partes no sometieron a su conocimiento) y, que generalmente, no permite una revisión de fondo de la decisión adoptada por los árbitros (Gonçalves Pereira, 2001). 
Consideramos pertinente resaltar como el artículo 3 de la Ley de Arbitraje Comercial venezolana (1998), enumera las controversias cuyo conocimiento y solución están excluidas del arbitraje:

a) Las que sean contrarias al orden público o versen sobre delitos o faltas, salvo sobre la cuantía de la responsabilidad civil, en tanto ésta no hubiere sido fijada por sentencia definitivamente firme;

b) Las directamente concernientes a las atribuciones o funciones de imperio del Estado o de personas o entes de derecho público;

c) Todas aquellas que versan sobre el estado o la capacidad civil de las personas;

d) Las relativas a bienes o derechos de incapaces, sin previa autorización judicial y;

e) Finalmente, quedan excluidas las controversias sobre las que haya recaído sentencia definitivamente firme, salvo las consecuencias patrimoniales que surjan de su ejecución en cuanto conciernan exclusivamente a las partes del proceso y no hayan sido determinadas por sentencia definitivamente firme.

\section{EL PRINCIPIO KOMPETENZ - KOMPETENZ}

Una de las principales condiciones para la eficacia del arbitraje comercial internacional, está en la posibilidad de invocar la existencia de una cláusula arbitral cuando una de las partes intenta desconocer la existencia de la misma. Es aquí donde adquiere la importancia el principio kompetenz - kompetenz, entendido como "la potestad que tiene el tribunal arbitral para decidir sobre su propia competencia, al igual que, sobre las excepciones referentes a la existencia o a la validez del acuerdo de arbitraje" (Fernández Rozas, Arenas García, \& Miguel Asensio, 2007, p. 649).

Es de considerar igualmente, que el principio en estudio se relaciona con el principio de autonomía del convenio arbitral (severability). Con fundamento en este último, el acuerdo de arbitraje debe entenderse separado del contrato del que pueda formar parte, de forma tal que la nulidad de dicho contrato no podrá afectar la validez de la cláusula arbitral. Se asevera así que, la coexistencia de los principios 
kompetenz - kompetenz y autonomía del acuerdo arbitral son una garantía de la operatividad y subsistencia de la institución del arbitraje comercial (Ramírez, 2010).

El principio Kompetenz-Kompetenz nace producto de una sentencia emitida por el Tribunal Superior de la República Federal de Alemania en el año 1955. En dicho fallo se estipuló que debía concedérseles a los árbitros la potestad de establecer el alcance del acuerdo arbitral que se somete a su conocimiento, como también, de su competencia y autoridad hacia el mismo. Este principio le da autoridad a los propios árbitros de decidir sobre su propia competencia cuando alguna parte invoca: la nulidad, la inexistencia o la ineficacia del pacto arbitral o bien cuando se alegue que una determinada materia no es susceptible de resolverse por medio de arbitraje (Sierra Ballmann, 2005). Encontramos aquí la relevancia del principio kompetenz - kompetenz, ya que este contribuye a que exista un control de los árbitros sobre su propio ámbito de acción, al ser ellos los primeros en resolver sobre su competencia.

De este principio se deriva que, si el tribunal arbitral es competente para pronunciarse sobre el acuerdo arbitral y resolver la controversia, la jurisdicción ordinaria, será entonces incompetente (Pereznieto Casto \& Graham, 2007).

Son la escuela alemana y la escuela francesa las que han estudiado con profundidad el principio kompetenz - kompetenz. Para la primera, este principio lleva consigo que el árbitro debe ser el único con capacidad para decidir sobre su competencia. La escuela francesa por su parte, matiza el alcance de este principio al determinar que el árbitro debe ser el primero en decidir sobre su competencia; luego, esta decisión queda sujeta a la determinación final que realice el juez ordinario, sin precisar en qué momento debe establecer su decisión (Martínez Cárdenas, 2007, pp. 57-ss).

En la actualidad la tendencia de la escuela alemana es la acogida en tratados internacionales y en las legislaciones nacionales. Es así como el artículo 16.1 de la Ley Modelo de la CNUDMI sobre Arbitraje Comercial Internacional de 1985, con enmienda de (2006), determina que el tribunal arbitral tiene la facultad "para decidir acerca de su propia competencia, incluso sobre las excepciones relativas a la existencia o a la validez del acuerdo de arbitraje". 
El Convenio sobre el Reconocimiento y Ejecución de Sentencias Arbitrales Extranjeras, Nueva York, de 10 de junio de (1958), incorporada al sistema jurídico venezolano mediante Ley Aprobatoria de 1984, en su artículo II numeral .3 prevé que:

"El tribunal de uno de los Estados contratantes al que se someta un litigio respecto del cual las partes hayan concluido un acuerdo en el sentido del presente artículo, remitirá a las partes al arbitraje, a instancia de una de ellas, a menos que compruebe que el acuerdo es nulo, ineficaz o inaplicable".

El artículo 7 de la Ley de Arbitraje Comercial venezolana establece que el tribunal arbitral tiene la potestad para decidir sobre su propia competencia; inclusive, sobre las excepciones relativas a "la existencia o a la validez del acuerdo de arbitraje". Además, determina que el acuerdo de arbitraje es independiente al contrato del cual forma parte, señalando que la decisión del tribunal arbitral acerca de la nulidad del contrato no conlleva la nulidad también del acuerdo arbitral (1998).

Luego, el principio kompetenz - kompetenz queda reiterado en el artículo 25 de la Ley antes señalada, añadiendo que:

"La excepción de incompetencia del tribunal arbitral deberá ser presentada dentro de los cinco días hábiles siguientes a la primera audiencia de trámite. (...), las partes no estarán impedidas para oponer la excepción porque se haya designado a un árbitro o participado en su designación. (...) por lo que, el tribunal arbitral podrá, en cualquiera de los casos, conocer una excepción de incompetencia del tribunal arbitral presentada fuera del lapso si considera justificada la demora" (Ley de Arbitraje Comercial, 1998).

\section{SENTENCIAS DEL TSJ VENEZOLANO Y EL PRINCIPIO KOMPETENZ - KOMPETENZ EN EL ARBITRAJE COMER- CIAL INTERNACIONAL}

Analizaremos a continuación las sentencias más relevantes que ha dictado el TSJ venezolano, relacionadas con el principio kompetenz - kompetenz en el arbitraje comercial internacional, desde el año 1999 cuando se creó este renovado Tribunal con autonomía financiera y funcional, dividido en siete Salas: Plena, de Casación Civil, de Casación Penal, de Casación Social, Constitucional, Electoral y Político Administrativa. 


\subsection{Línea jurisprudencial del TSJ venezolano que negó u omitió el principio kompetenz - kompetenz en el arbitraje comercial inter- nacional}

Es evidente una primera línea de fallos dictados por la Sala Político -Administrativa (SPA) del TSJ, que demarcan una tendencia a la negación u omisión del principio kompetenz - kompetenz en el arbitraje comercial internacional.

\subsubsection{Asunto Hyundai de Venezuela C.A.C. Hyundai Motor Company}

En el fallo Venezuela, Tribunal Supremo de Justicia, Sala Político Administrativa, sentencia del 21 de octubre de 1999, magistrada ponente Hildegard Rondón de Sansó, Expediente 15300, se decidió sobre una demanda que interpuso Hyundai de Venezuela, C.A., domiciliada en Venezuela, ante el TSJ venezolano en el año 1997 contra Hyundai Motor Company, constituida bajo las leyes de la República de Corea del Sur y cuya sede principal se ubicaba en Seúl.

Ambas empresas habían celebrado un contrato en virtud del cual Hyundai de Venezuela, C.A., había sido nombrada distribuidor exclusivo para Venezuela de todos los productos de Hyundai Motor Company, detallando en el mismo los derechos y obligaciones de ambas partes. No obstante, Hyundai de Venezuela alegó en su demanda que luego de una cuantiosa inversión y de haber realizado el lanzamiento de esa nueva marca de vehículos en el país sudamericano, Hyundai Motor Company suspendió arbitrariamente la relación comercial para otorgar similar contrato a una firma automotriz con la que estaba vinculada por antiguas relaciones comerciales y económicas.

La demandante, entre otros puntos, alegó que la demandada pretendía desconocer su obligación de indemnización y que había incurrido en el ilícito mercantil de abuso de derecho. Además, invocó la competencia de los tribunales venezolanos para conocer del caso, ya que el fundamento de la demanda derivaba de un contrato ejecutado en el territorio venezolano.

Hyundai Motor Company en el plazo procesal pertinente interpuso cuestiones previas. Opuso la falta de jurisdicción del juez ordinario venezolano, contemplada en el ordinal $1^{\circ}$ del artículo 346 del Código de Procedimiento Civil venezolano, CPC, (1990), alegando que las partes había acordado que las diferencias que pudiesen surgir entre 
ellas con motivo del convenio de distribución serían sometidas a arbitraje. Añadiendo que, en dicho contrato, específicamente en la sección veinticuatro (24), se había establecido con toda claridad que el arbitraje se llevaría a cabo en Seúl, Corea.

La SPA del TSJ venezolano determinó que el contrato celebrado había perdido vigencia y por ello era posible que entre las partes se originaran relaciones no vinculadas al contrato original. En tal sentido, las relaciones suscitadas entre las partes posteriormente a la pérdida de vigencia del contrato, no guardaban relación con el mismo; es decir, habían nacido entre las partes deberes y obligaciones que no fueron producidos por el contrato y, por tanto, no podía este serles aplicable.

Estimó la Sala, que la cláusula 24.2 donde se establecía que cualquier disputa o reclamo surgido de o en relación con el convenio de distribución o cualquier violación del mismo, sería saldado definitivamente mediante arbitraje, no era extensible a todas las reclamaciones que sustentaban la demandada, sino solamente a aquellas que eran consecuencia de actuaciones suscitadas dentro del marco temporal del contrato. Por lo cual una vez concluido el mismo, no era posible aplicar la cláusula in comento a relaciones posteriores.

Por otra parte, para la SPA, en el caso se alegaba el incumplimiento de deberes genéricamente protegidos por el legislador venezolano, como lo eran la buena fe en la contratación y la represión del abuso de derecho, lo cual según había expresado la parte demandante, habían sido vulnerados en un ámbito extracontractual (fuera de la aplicación del convenio de distribución), lo cual evidenciaba que no estaba en disputa el cumplimiento del contrato celebrado.

Fue dentro de la anterior óptica que la SPA, dictaminó la imposibilidad de aplicar la cláusula 24.2 del contrato, por lo cual determinó la jurisdicción de los tribunales venezolanos con fundamento en el numeral 2 del artículo 40 de la Ley de Derecho Internacional Privado (Ley Especial, 1998).

En definitiva, dicha Sala del TSJ venezolano desconoció el principio de autonomía del convenio arbitral (severability) en relación con el contrato y, asimismo, omitió el principio kompetenz - kompetenz estipulado en el artículo 7 y 25 de la Ley de Arbitraje Comercial venezolana. Es decir, excluyó la potestad que tenían los árbitros para conocer sobre su propia competencia y sobre la validez del acuerdo arbitral. 


\subsubsection{Asunto Consorcio Barr S.A C. Four Seasons Caracas C.A.}

En esta sentencia, (2003) la SPA reiteró su criterio según el cual, para la validez de la cláusula compromisoria o acuerdo arbitral en un contrato, debía existir una manifestación de voluntad inequívoca y expresa de las partes, de sustraer el conocimiento de la causa de los tribunales ordinarios. Esto es porque, a criterio de la Sala, el arbitraje era una excepción a la competencia constitucional que tenían los tribunales ordinarios venezolanos de resolver por imperio de la ley, todas las demandas que les eran sometidas por los ciudadanos para su conocimiento, en uso del derecho constitucional a la tutela judicial efectiva de sus derechos e intereses, previsto en el artículo 26 de la Constitución de la República Bolivariana de Venezuela de 1999 (Araúz Ramos, 2014).

La cláusula 19.03 del contrato celebrado entre el Consorcio Barr S.A c. Four Seasons Caracas C.A., disponía que toda disputa sería resuelta por arbitraje celebrado en la Ciudad de Miami, Florida, Estados Unidos de América o en la Ciudad de Caracas, República de Venezuela, según fuese el caso, y sería conducido en el idioma inglés. Además, preveía que salvo por los procedimientos específicamente indicados en la misma sección 19.03, sería conducido de acuerdo con las Reglas de Arbitraje Mercantil de la Asociación Americana de Arbitraje.

Ahora bien, la SPA consideró que de la cláusula 19.03 del contrato antes citada, se desprendía que ciertos asuntos podrían sustraerse o no del conocimiento del poder judicial, lo cual acreditaba una situación de inseguridad jurídica para las partes. La Sala consideró que la cláusula invocada por la representación de la parte demandada, a los fines de la derogación de la jurisdicción que correspondía a los tribunales venezolanos para conocer el asunto, carecía de la eficacia jurídica necesaria a tales fines. Fue así que volvió a descocer el acuerdo de arbitraje comercial celebrado entre las partes con las consecuencias jurídicas implícitas que ello significó.

\subsubsection{Asunto Consultores Occidentales S.A (COSA) y Constructores Venezolanos, C.A. (CONVECA) c. Hanover P.G.N Compressor, C.A.}

Este caso estaba fundamentado en la demanda por incumplimiento de contrato interpuesta por COSA y CONVECA contra Hanover P.G.N Compressor, C.A. 
Luego la demandada opuso la cuestión previa contenida en el ordinal $1^{\circ}$ del artículo 346 del CPC, referida a la falta de jurisdicción del Tribunal de la causa, por cuanto alegaba la existencia de una cláusula compromisoria que atribuía el conocimiento del asunto a un órgano arbitral. La demanda tenía por objeto el cumplimiento de un contrato de obra suscrito entre las partes, el cual en su Cláusula Décima Novena disponía:

Cualquier disputa o controversia que surja en relación con el presente contrato será sometida a la decisión de tres (3) árbitros de derecho, de conformidad con las normas de arbitraje de la Cámara Internacional de Comercio, cuya decisión será definitiva e inapelable. Dentro de los quince (15) días siguientes a la fecha en que se produzca la disputa o controversia, cada una de las Partes designará un árbitro y dentro de los quince (15) días siguientes a dicha designación, los dos (2) árbitros así elegidos, nombrarán al tercer árbitro. Cada parte correrá con los honorarios y gastos del árbitro que ha nombrado y el $50 \%$ de los honorarios y gastos del tercer árbitro. El arbitraje se realizará en Caracas, Venezuela y la decisión de los tres miembros del tribunal arbitral. Si las normas de arbitraje comercial de la Cámara Internacional de Comercio estuvieren en conflicto con los términos de este contrato, prevalecerán las disposiciones del mismo (Tribunal Supremo de Justicia, Sala Político Administrativa, 2003).

Aunque el acuerdo arbitral pactado por las partes contratantes preveía que tanto el arbitraje como la decisión de los árbitros se llevarían a cabo en la ciudad de Caracas, su internacionalidad claramente venía dada al estipularse que las controversias que surgiesen en relación con el contrato en cuestión, serían sometidas a la decisión de tres (3) árbitros de derecho, de conformidad con las normas de arbitraje de la Cámara Internacional de Comercio. La SPA, sin embargo, declaró sin lugar la cuestión previa opuesta por la demandada, al considerar que los únicos casos en los cuales el Juez puede declarar su falta de jurisdicción son los previstos en el artículo 59 del CPC, esto era, frente a la Administración y frente al Juez extranjero, criterio que ha sido abandonado por la actual tendencia jurisprudencial. ${ }^{51}$

51 Es oportuno explicar que dentro del sistema jurídico de Venezuela se debate sobre si para exigir la validez del acuerdo de arbitraje debe incoarse una excepción por falta de jurisdicción (artículo 59 del CPC) o la primera cuestión previa enumerada en el artículo 346 del CPC y sí, en consecuencia, operaría la regulación de jurisdicción fijada en el artículo 62 y siguientes ejusdem. Sin embargo, como lo corrobora la tendencia que estudiaremos más adelante, por ejemplo en el asunto Astivenca 
Dicha Sala estimó que, ante la solicitud por parte de la demandada de declarar la falta de jurisdicción del tribunal ordinario, en virtud de la existencia de una cláusula compromisoria, resultaba necesaria la aplicación del procedimiento previsto en el artículo 609 y siguientes del CPC, a los fines de determinar la validez de la referida cláusula.

Entonces concluyó la SPA, que de conformidad con lo dispuesto en los artículos 608, 609 y 628 del CPC y el primer aparte del artículo 5 de la Ley de Arbitraje Comercial venezolana, el Juez de la causa tendría jurisdicción y competencia para determinar la validez o no del acuerdo arbitral, si se oponía ante él la prevalencia de dicha cláusula como medio para resolver la controversia, cumpliendo y verificando la manifestación de voluntad expresa de las partes involucradas.

En nuestra opinión resulta evidente, que la interpretación de la SPA antes expuesta negó la esencia misma del principio kompetenz - kompetenz del arbitraje comercial, en este caso internacional.

\subsubsection{Asunto Procuraduría General de la República Bolivariana de Venezuela c. Autopista Concesionada de Venezuela AUCOVEN C.A.}

En la decisión Venezuela, Tribunal Supremo de Justicia, Sala Político Administrativa, sentencia del 18 de noviembre de 2003, magistrado ponente Levis Ignacio Zerpa, Expediente 2001-0943, la República Bolivariana de Venezuela intentó una acción mero declarativa contra la sociedad mercantil Autopista Concesionada de Venezuela, C.A., con el objetivo que se declarase la resolución de un contrato de concesión, suscrito entre las partes en el año 1996, para el proyecto de construcción, explotación, conservación y mantenimiento del Sistema Vial Autopista Caracas-La Guaira y carretera vieja Caracas-La Guaira y de sus servicios conexos.

La demandada en la oportunidad para la contestación de la demanda, opuso la cuestión previa del ordinal $1^{\circ}$ del artículo 346 del CPC, relativa a la falta de jurisdicción del Juez. Alegando que había suscrito

Astilleros de Venezuela, C.A. c. Oceanlink Offshore III A/S, el TSJ venezolano actualmente se inclina por admitir la excepción del arbitraje como una cuestión previa por falta de jurisdicción del juez, prevista en el ordinal primero de artículo 346 del CPC y aceptar la regulación desarrollada en el artículo 62 y siguientes del CPC (Tribunal Supremo de Justicia, Sala Constitucional, 2010). 
un contrato de concesión con la República Bolivariana de Venezuela y que según la cláusula 64 del mismo, las partes habían acordado que someterían las controversias que surgieren a arbitraje de conformidad con el Convenio CIADI y las correspondientes Reglas de Arbitraje del Centro Internacional de Arreglo de Diferencias Relativas a Inversiones. Resulta evidente entonces, que este asunto giraba en torno a un acuerdo de arbitraje de inversión ${ }^{52}$. La SPA en esta sentencia determinó que la cláusula número 64 del contrato de concesión, que contenía un acuerdo arbitral de inversión invocado por la demandada con la intención de sustraer del conocimiento de los tribunales venezolanos la controversia, carecía de eficacia.

Así pues, la Sala aplicó lo dispuesto en el artículo 10 del Decreto Ley $N^{\circ} 138$ sobre Concesiones de Obras Públicas y Servicios Públicos Nacionales, el cual dispone que: "El concesionario estará sometido al ordenamiento jurídico venezolano y a la jurisdicción de los Tribunales de la República” (Decreto Ley 138, 1994), y, por tanto, declaró que el Poder Judicial sí tenía jurisdicción para conocer de la referida acción mero declarativa interpuesta por el mismo Estado venezolano. Resulta incuestionable que existió un panorama poco alentador dentro del sistema jurídico venezolano en relación a la institución del arbitraje comercial internacional. Específicamente, porque la Sala Político Administrativa del TSJ desde su conformación en 1999, en cuatro de sus sentencias negó la potestad que tiene el tribunal arbitral para decidir sobre su propia competencia y sobre la validez del acuerdo arbitral.

\subsection{Línea Jurisprudencial del TSJ venezolano que reconoció el prin- cipio kompetenz - kompetenz en el arbitraje comercial internacional}

Existe otra corriente jurisprudencial del TSJ venezolano que sí ha favorecido el principio kompetenz - kompetenz en el arbitraje comercial internacional y es la que se ha consolidado en la actualidad. Esta tendencia proviene de la SPA y la Sala Constitucional (SC) de ese Máximo Tribunal.

52 El arbitraje de inversión se verifica cuando una de las partes es el gobierno de un país que ha suscrito y ratificado el Convenio sobre Arreglo de Diferencias Relativas a Inversiones entre Estados y Nacionales de otros Estados, celebrado bajo el seno del Banco Mundial en Washington en 1965 (Araque Benzo, 2011, pp. 22-24). Es de mencionar que la República Bolivariana de Venezuela ratificó este Convenio el 3 de abril de 1995 y lo denunció el 24 de enero de 2012. 


\subsubsection{Asunto Astivenca Astillero de Venezuela, C.A c. Oceanlink Offshore III As. (SPA)}

En este caso la sociedad mercantil Astivenca Astilleros de Venezuela, C.A., incoó demanda por incumplimiento de contrato e indemnización por daños y perjuicios, contra la sociedad mercantil Oceanlink Offshore III A/S en el año 2008. Además, solicitó medida de prohibición de zarpe y el embargo preventivo de la embarcación M/N Nobleman. El Tribunal de Primera Instancia Marítimo con competencia nacional y con sede en la ciudad de Caracas admitió la demanda, decretando la medida de prohibición de zarpe, pero negando la medida de embargo preventivo.

Dentro del lapso fijado para la contestación de la demanda, Oceanlink y del capitán de la embarcación M/N Nobleman compareció, alegando que la citación practicada estaba viciada, además presentó escrito de oposición a la medida cautelar. El Tribunal de Primera Instancia Marítimo con competencia nacional repuso la causa al estado en que transcurriera el término de la comparecencia de la parte demandada, más un término de distancia de cuatro días. Luego, la demandada opuso cuestiones previas, destacando la de falta de jurisdicción del juez ordinario, previsto en el ordinal $1^{\circ}$ del artículo 346 del CPC. Este alegato se fundamentaba en la existencia de una cláusula arbitral en el Memorando de Entendimiento suscrito entre las partes. El Tribunal de Primera Instancia Marítimo con sede en la ciudad de Caracas, en su Sentencia de 2009 declaró con lugar la cuestión previa opuesta por la parte demandada; por tanto, declaró que el Poder Judicial no tenía jurisdicción para conocer el caso. No obstante, el fallo omitió la medida cautelar decretada, por lo cual la parte demandada solicitó una ampliación de la sentencia, la cual fue dictada posteriormente.

El 20 de febrero de 2009 la demandante interpuso recurso de regulación de jurisdicción contra la decisión del Tribunal de Primera Instancia Marítimo, el cual acordó remitir todas las actuaciones a la SPA del TSJ. El basamento del recurso de regulación de jurisdicción interpuesto era que Oceanlink se había sometido tácitamente a la jurisdicción de los tribunales venezolanos, en virtud que su primera actuación fue la de oponerse a la medida cautelar decretada en su contra y oponer la defensa de falta de legitimidad del citado. También alegó la demandante, que en aplicación del artículo 11 de la Ley de Comercio Marítimo (2006), los tribunales venezolanos tenían jurisdicción exclusiva para decidir sobre la controversia, porque el buque objeto de la acción se encontraba en aguas venezolanas. La SPA del TSJ dictó su 
sentencia el 21 de mayo (2009), determinando que ciertamente el caso presentaba elementos de extranjería relevantes, como el domicilio de la parte demandada (ciudad de Oslo -Noruega) y el objeto del contrato de compra-venta contenido en el Memorando de Entendimiento suscrito entre las partes, como lo era el buque Nobleman, el cual se encontraba registrado en Douglas, capital de la Isla de Man. Por ello, la SPA aseveró que podrían resultar aplicables las disposiciones contenidas en los artículos 39 y siguientes de la Ley de Derecho Internacional Privado venezolana, las cuales regulaban los supuestos en los que los tribunales venezolanos tenían jurisdicción. No obstante, para la SPA también debía considerarse que la parte demandada invocó la cláusula 16 del contrato, que contenía una cláusula de arbitraje. Esta determinaba que el acuerdo sería regido e interpretado según la ley inglesa y cualquier disputa originada por el mismo, sería referida a un arbitraje en Londres. Por esta última razón, la SPA determinó en su sentencia que el Poder Judicial venezolano no tenía jurisdicción para conocer del caso.

Fue así que la SPA confirmó la decisión dictada por el Juzgado de Primera Instancia Marítimo, que declaró con lugar la cuestión previa de falta de jurisdicción opuesta por la demandada. Además, ratificó el fallo que dejaba sin efecto la medida cautelar de prohibición de zarpe del buque M/N Nobleman. La SPA en su decisión expresó que las exposiciones de la parte demandada en su primera actuación, si bien no consistieron en oponer la cuestión previa de falta de jurisdicción, tampoco estaban destinadas a ejercer defensas de fondo; de allí que, dictaminó que no había evidencia en los autos que la parte demandada haya querido renunciar, ni tácita ni expresamente, al arbitraje (Figuera Vargas, 2013).

\subsubsection{Asunto Astivenca Astillero de Venezuela, C.A. c. Oceanlink Offshore III As. (SC)}

Frente a la sentencia anteriormente expuesta, la parte demandante interpuso recurso de revisión ante SC del TSJ, por considerar que la decisión de la SPA había vulnerado el principio de confianza legítima, el derecho a la igualdad y a la seguridad jurídica. Estimó el peticionario, que el criterio pacífico y reiterado de la SPA referido a la sumisión tácita a la jurisdicción ${ }^{53}$ no había sido aplicado en este caso. En opinión de la demandante la SPA modificó su criterio, donde afirmaba que

53 Criterio adoptado por ejemplo en: la sentencia del expediente No. 02-0365 (Tribunal Supremo de Justicia, Sala Político Administrativa, 2002). 
cualquier actuación distinta a la oposición de la falta de jurisdicción como acto inicial del proceso por parte del demandado, constituía una renuncia tácita de la cláusula arbitral.

Fue así que entró a conocer de la controversia la SC del TSJ venezolano y en el caso No. 09-0573, (2010), determinó que el principio kompetenz - kompetenz permitía al tribunal arbitral decidir acerca de su propia competencia (independientemente de lo que sostenga un tribunal nacional), incluso sobre las relativas a la existencia o a la validez del acuerdo de arbitraje.

Para la Sala, resultaba evidente dos perspectivas de este principio, una positiva, referida a la potestad de los árbitros de resolver sobre su propia competencia aun respecto a cuestiones relativas a la validez o existencia del acuerdo de arbitraje (Ley de Arbitraje Comercial,1998, Art. 7 y 25) y una negativa, conforme a la cual los tribunales no deben decidir en paralelo y con el mismo grado de profundidad sobre la validez, eficacia o aplicabilidad que los órganos arbitrales (Artículo II.3 de la Ley Aprobatoria de la Convención sobre el Reconocimiento y Ejecución de las Sentencias Arbitrales Extranjeras.

Ahora bien, para Sala Constitucional la cuestión no radicaba en determinar la existencia o no del principio kompetenz - kompetenz en el ordenamiento jurídico venezolano, sino su aplicación en aquellos casos en los cuales una de las partes que acordó someter a arbitraje todas las diferencias o ciertas diferencias que pudiesen surgir o pudiesen generarse entre ellas respecto a una determinada relación jurídica, contractual o no contractual, luego decide acudir e iniciar un proceso ante los órganos del Poder Judicial (Tribunal Supremo de Justicia, Sala Constitucional, 2010).

La SC decidió que sobre la base del principio kompetenz - kompetenz, en las relaciones "(...) de coordinación y subsidiariedad de los órganos del Poder Judicial frente al sistema de arbitraje, dichos órganos solo podían realizar un examen o verificación prima facie, formal, de los requisitos de validez, eficacia y aplicabilidad de la cláusula arbitral. Esta debía limitarse a la constatación del carácter escrito del acuerdo de arbitraje y se excluía cualquier análisis relacionado con los vicios del consentimiento que deriven de la cláusula” (Araúz Ramos, 2014, p. 315). 
Este criterio de la SC tiene carácter vinculante conforme a las consideraciones expuesta esta decisión, por lo que, a partir de su publicación en la Gaceta Oficial, en el sistema jurídico venezolano no son aplicables los criterios jurisprudenciales sostenidos en esta materia por la SPA del TSJ hasta esa fecha.

\section{CONCLUSIONES}

Con la entrada en vigencia de la Constitución de la República Bolivariana de Venezuela en 1999, sus artículos 253 y 258, incluyeron en el sistema de administración de justicia a los medios alternativos de resolución de conflictos, exhortándose su promoción a través de la ley.

Al ampliar la Constitución de Venezuela el sistema de justicia, incluyendo al arbitraje como parte de la función judicial, se modificó el modelo de sistema de justicia, que buscaba lograr una descongestión de la justicia ordinaria y, que el arbitraje ya fuera percibido como una institución que no llega a brindar una tutela jurisdiccional eficaz (Araúz Ramos, 2014).

Pero a pesar de las afirmaciones antes expuestas, en este estudio se concluyó que en la primera década del siglo XXI en las sentencias del TSJ se verificó una tendencia negativa a la aplicación del principio kompetenz - kompetenz en el arbitraje comercial internacional. No obstante, esa línea jurisprudencial negativa en las últimas sentencias del TSJ se ha desvanecido; es así como, la SPA y la SC de este Máximo Tribunal han respaldado la correcta interpretación y aplicación del principio kompetenz - kompetenz en el sistema jurídico venezolano.

Una evidente corriente positiva a favor de este principio se consagró en la decisión Venezuela, Tribunal Supremo de Justicia, Sala Constitucional, sentencia del 3 de noviembre de 2010, magistrada ponente Luisa Estella Morales Lamuño, Expediente 09-0573, donde se dictaminó que con fundamento al principio kompetenz - kompetenz; así como, en las relaciones de coordinación y subsidiariedad de los órganos del Poder Judicial frente al sistema de arbitraje, dichos órganos sólo podían realizar un examen o verificación prima facie, formal, de los requisitos de validez, eficacia y aplicabilidad de la cláusula arbitral. 


\section{REFERENCIAS BIBLIOGRÁFICAS}

Araque, L. (2011). Manual de arbitraje comercial. Caracas: Editorial Jurídica Venezolana.

Araúz, J. (2014). Constitucionalización y Justicia Constitucional en el Arbitraje Comercial Panameño. Tesis Doctoral. Madrid: Universidad Complutense de Madrid Facultad de Derecho. Departamento de Derecho Internacional Público y de Derecho Internacional Privado. Obtenido de http://eprints.ucm.es/24527/1/T35113.pdf.

Betancourt, M. (2010). Aportes del CEDCA al arbitraje institucional en Venezuela. Revista de la FCJP de la Universidad Monteávila, Derecho y Sociedad, Negociación, Mediación y Arbitraje.

Congreso de la República de Venezuela (1994). Decreto Ley 138.

Congreso de la República de Venezuela (1990). Código de Procedimiento Civil.

Congreso de la República de Venezuela (1998). Ley de Arbitraje Comercial.

Congreso de la República de Venezuela. (2006) Ley Especial.

Congreso de la Rpública de Venezuela (1984). Ley Aprobatoria.

Constitución de la República Bolivariana de Venezuela (1999).

Fernández, J., Arenas, R., y Miguel, P. (2007). Derecho de los negocios internacionales. Madrid: Iustel.

Figuera, S. (2013). El arbitraje comercial internacional y la falta de jurisdicción de los órganos del Poder Judicial: Sentencia no 1.067/2010 de la Sala Constitucional del Tribunal Supremo de Justicia venezolano. Arbitraje. Revista arbitraje comercial y de inversiones.

Gonçalves, C. (2001). El arbitraje: ¿Qué es y Cuáles son sus ventajas e inconvenientes? Obtenido de www.icex.es: http://www.icex.es/icex/ wcm/idc/groups/public/documents/documento_anexo/mde0mjk x/ edisp/dax2014291090.pdf. 
Hung, F. (2001). Reflexiones sobre el arbitraje en el sistema venezolano. Caracas: Editorial Jurídica Venezolana.

Martínez, I. (2007). Kompetenz-Kompetenz: ¿Quién debe resolver acerca de la validez de un convenio arbitral? Lima: Biblioteca Estudios de Arbitraje.

Naciones Unidas CNUDMI (2006). Ley Modelo.

Naciones Unidas UNCITRAL (1958). Convención sobre el Reconocimiento y la Ejecución de las Sentencias Arbitrales Extranjeras. Nueva York.

Pereznieto, L., y Graham, J. (2007). El principio de la competencia arbitral en la actualidad mexicana. Obtenido de limaarbitration.net: http://limaarbitration.net/LAR2/leonel_pereznieto_castro_james_a_graham.pdf

Ramírez, J. (2010). Tres Aspectos Positivos de la Nueva Jurisprudencia Constitucional en Materia de Arbitraje. Revista de la FCJP de la Universidad de Monteávila, Derecho y Sociedad, Negociación, Mediación y Arbitraje.

Sánquiz, S. (2005). El derecho aplicable al arbitraje comercial internacional en el derecho venezolano. Caracas: Fundación Roberto Goldschmidt, Universidad Católica Andrés Bello.

Sierra, D. (2005). El principio Kompetenz - Kompetenz en el Arbitraje. Obtenido de Guatemala, Universidad Francisco Marroquín, Facultad de Derecho: http://www.tesis.ufm. edu.gt/ derecho/2005/ 76493/tesis.html

Tribunal Supremo de Justicia, (2010) Sala Constitucional, Expediente No. 09-0573, magistrada ponente Luisa Estella Morales Lamuño..

Tribunal Supremo de Justicia, (1999) Sala Político Administrativa, Expediente No.15300, magistrada ponente Hildegard Rondón de Sansó.

Tribunal Supremo de Justicia, (2002) Sala Político Administrativa, 02-0365, magistrado ponente Hadel Mostafá Paolini..

Tribunal Supremo de Justicia, (2003) Sala Político Administrativa, 2003-0044, magistrado ponente Levis Ignacio Zerpa.. 
Tribunal Supremo de Justicia, (2003) Sala Político Aministrativa, 2000-1244, magistrado ponente Hadel Mostafá Paolini..

Tribunal Supremo de Justicia, (2009) Sala Político Aministrativa, 2009-0188, magistrado ponente Levis Ignacio Zerpa.

Valeri Albornoz, P. (2011). Curso de Derecho Mercantil. Caracas: Ediciones Liber.

Recibido: 29 de junio de 2018

Aceptado: 7 de noviembre de 2018

Dra. Sorily Carolina Figuera Vargas, PhD: Doctora en Derecho, Universidad de Salamanca; máster en Derecho Internacional Privado y Comparado, Universidad Central de Venezuela; máster en Derecho Internacional y Relaciones Internacionales, Universidad Complutense de Madrid. Abogada, Universidad Bicentenaria de Aragua, Venezuela; Licenciada en Derecho en España. Profesora a tiempo completo de la Facultad de Jurisprudencia de la Pontificia Universidad Católica del Ecuador.

Correo electrónico: sfiguera425@puce.edu.ec

Dra. Sonia Vargas Torres: Abogada de la Universidad José Antonio Páez, Venezuela. Investigadora del Instituto Jurídico Bartolomé de las Casas, Venezuela.

Correo electrónico: sonia_vargas53@hotmail.com

Juan Fernando Puertas Barahona: Estudiante en la Pontificia Universidad Católica del Ecuador facultad de Jurisprudencia.

Correo electrónico: jpuertas626@puce.edu.ec 